\title{
Re-evaluation on Causes of Circular Knitting Machine Production Efficiency and their Impact on Fabric Quality
}

\author{
Md. Anisuzzaman Rassel, \\ BSc in Textile Engineering, Manager, Research and Development, Alpi \\ Fashion Sourcing, Bangladesh \\ Mohammad Mohsin Ul Hoque, \\ MSc in Textile Engineering, Faculty Member, \\ National Institute of Textile Engineering and Research, Bangladesh
}

Doi:10.19044/esj.2019.v15n21p448 URL:http://dx.doi.org/10.19044/esj.2019.v15n21p448

\begin{abstract}
:
The productivity of knitting machine depends on yarn type and its quality, knitting parameters, operating conditions, workplace safety measures, and motivational factors of workforce. For several reasons, knitting machine can stop working and the production process is interrupted. In this paper, it was found that the main reason for yarn breakage is the condition of the working environment in which it operates. Yarn breakage is not only responsible for production losses, but it also creates quality problems on fabric texture. Quality is money as it is interlinked with reputation. In order to survive in a competitive market, it is important to analyse and resolve the root causes which can hamper production efficiency. Environmental factors are involved with knitted fabric production efficiency. Less production efficiency enhances more power consumption and other utilities. As a consequence, the cost of pollution on our environment is rising. This paper shows that causes of production loss and efficiency interruptions is due to different conditions of working environment and other facilities which can motivate employees to work efficiently in their workstations.
\end{abstract}

Keywords: Knitted fabric, productivity, efficiency loss, single jersey, operating condition, quality fabric

\section{Introduction}

In order to produce textile fabrics, the most versatile method of manufacturing used is mechanical manipulation of yarn into fabric, e.g., interweaving, intertwining, and inter-looping. Interweaving is the intersection of two sets of straight threads, one is in a horizontal way called weft and the 
other is in a vertical way called warp. Intertwining technique is used to intertwine minimum of three sets of yarn with each other at right angles or some other angle. Inter-looping or knitting is the structural clothing piece which is constructed by interlocking of one set of yarn (Prasad \& Kumar, 2016).

Knitting is the second most commonly used method of fabric construction. Knitted fabrics have been gaining popularity because of its comfortable properties. Nowadays, the usage of knitted fabrics ranges from hosiery, formalwear and casual wear, sleeping wear, leisurewear, underwear, sweaters, slacks, sportswear, and other home furnishings (Spencer David, 2001).

Additionally, compared to woven fabrics, it is possible to produce knitted fabrics in less time due to its air permeability and stretchable properties. Knit fabric manufacturing is divided into two distinct sectors, i.e. weft knitting and warp knitting. Loops are formed in horizontal direction across the width of the fabric, and each weft yarn is fed more or less at a right angle in weft knitting. In warp knitting, the loops are formed downward vertically to the length of the fabric from one thread to the width of the fabric across.

Generally, there are two types of knitting machine, i.e. circular knitting machine and flat-bed knitting machine. Main parts of circular weft knitting machines are creel, feeder, VDQ (variable diameter quality) pulley, guide, sensor, cylinder, and spreader. Creel is used for holding the yarn packages. Feeder, as the name implies, feeds the yarn as per demand of fabric structure and design. For controlling the loop length of the fabric, VDQ (variable diameter quality) pulley plays a vital role in the machine. Yarn guide is used to guide the yarn. Sensor is a mandatory automatic controlling system which detects yarn breakage and stops the machine. Cylinder carries three basic knitting elements named needle, cam, sinker and many more (Anbumani, 2007; Ray, 2011). In order to meet the demand of the buyer or retailer, the defect-free "Quality Fabric" is the main ingredient in a readymade garment that delights the consumer behaviour towards specific brand. Fashion designers primarily focus on the texture of the fabric. This is because the finished fabric is the raw material for the particular garment. Raw material selection, knitting input parameters with respect to material, machine and man are responsible for getting quality fabric (Fatkic, Gersak, \& Ujevic, 2011).

There are several reasons responsible for lessening of machine efficiency. The mentioned reasons are the main causes for lowering the productivity of the knitting machines which includes needle breakage, yarn breakage, improper machine gauge, yarn tension, yarn type, yarn count, yarn storage, fabric type, fabric structure and design, machine rpm, poor maintenance, and fabric handling. Besides these, operator skills, workplace 
environment and facilities, and same machine specifications with different machine manufacturer also affect efficiency of knitting production. In this study, six knit composite manufacturing units are examined which are $100 \%$ export oriented factory.

\section{Materials and Methods}

\subsection{Fabrics and Machinery}

To produce a single jersey $100 \%$ knitted fabric, four knitting machines are needed in both air-condition work environment and non air-condition work environment which are presented in the table below:

\begin{tabular}{|l|c|c|}
\hline $\begin{array}{l}\text { Air-condition } \\
\text { Environment }\end{array}$ & $\begin{array}{c}\text { Machine No. } \\
\text { P14 }\end{array}$ & $\begin{array}{c}\text { Machine No. } \\
\text { J29 }\end{array}$ \\
\hline Brand Origin & Taiwan & South Korea \\
\hline Dia X Gauge & 32 X 24 & 36 X 24 \\
\hline Feeders & 96 & 108 \\
\hline Safety RPM & 25 & 25 \\
\hline Fabric Type & single jersey & single jersey \\
\hline Stitch Length & $2.75 \mathrm{~mm}$ & $2.75 \mathrm{~mm}$ \\
\hline Yarn Count & $28 \mathrm{Ne}$ & $28 \mathrm{Ne}$ \\
\hline Finished GSM & 160 & 160 \\
\hline Non Air-condition & Machine No. & Machine No. \\
Environment & K35 & Z67 \\
\hline Brand Origin & China & China \\
\hline Dia X Gauge & 34 X 24 & 30 X 24 \\
\hline Feeders & 102 & 90 \\
\hline Safety RPM & 25 & 25 \\
\hline Fabric Type & single jersey & single jersey \\
\hline Stitch Length & $2.75 \mathrm{~mm}$ & $2.75 \mathrm{~mm}$ \\
\hline Yarn Count & $28 \mathrm{Ne}$ & $28 \mathrm{Ne}$ \\
\hline Finished GSM & 160 & 160 \\
\hline
\end{tabular}

Where stitch length is in mm, machine diameter is in inches and gauge is in needles per inch.

\subsection{Operating Environment}

Machine handling time by machine operator was monitored and recorded for both air- condition workplace and non air-condition workplace environment.

\subsection{Production Calculation}

The following formula is used to calculate production per hour: $($ No of Needle $\times$ No of Feeder $\times$ Stitch Length $\times$ Efficiency $\times R P M \times 60)$ $10 \times 2.54 \times 36 \times 840 \times$ Yarn Count $\times 2.2046$ 


\subsection{Efficiency Calculation}

It is the ratio between actual production and calculated production.

$$
\text { Efficiency }=\frac{\text { Actual Production }}{\text { Calculated Production }} \times 100
$$

Efficiency Losses (for a particular machine)

$$
=\frac{\text { Calculated Production }- \text { Actual Production }}{\text { Calculated Production }} \times 100
$$

\subsection{Quality Fabric Production}

Quality fabric production is one of the prime factors for any type of textile business. During knit fabric production, different fabric faults occur due to operating environment, production target, career challenges, and wage discrimination. These factors strongly influence man, machine, and materials.

\section{Result and Discussions}

\subsection{Production and Efficiency Calculation}

Calculated production time period per shift (where one shift is equal to eight hours) is $8 \times 60$ or 480 minutes.

Therefore, per day production period (three shifts a day) is $480 \times 3$ or 1440 minutes.

Calculated production per day for a single jersey machine (machine no. P14)

$$
=\frac{\pi x \text { dia } x \text { gauge } x \text { no. of feeder } x \text { stitch length } x \text { efficiency } \times \text { rpm } \times 1440}{10 \times 2.54 \times 36 \times 840 \times \text { Yarn Count } \times 2.2046}
$$

$$
=\frac{3.1416 \times 32 \times 24 \times 96 \times 2.75 \times 0.85 \times 25 \times 1440}{10 \times 2.54 \times 36 \times 840 \times 28 \times 2.2046}
$$

$=410.87 \frac{\mathrm{kg}}{\text { day }} \cong 411 \frac{\mathrm{kg}}{\mathrm{day}}$

Calculated production per day for a single jersey machine (machine no. J29)

$=\frac{\pi x \text { dia } x \text { gauge } x \text { no. of feeder } x \text { stitch length } x \text { efficiency } x \text { rpm } \times 1440}{10 \times 2.54 \times 36 \times 840 \times \text { Yarn Count } \times 2.2046}$

$$
\begin{aligned}
& =\frac{3.1416 \times 36 \times 24 \times 108 \times 2.75 \times 0.85 \times 25 \times 1440}{10 \times 2.54 \times 36 \times 840 \times 28 \times 2.2046} \\
& =520 \frac{\mathrm{kg}}{\text { day }}
\end{aligned}
$$

Calculated production per day for a single jersey machine (machine no. 35) 
$=\frac{\pi x \text { dia } x \text { gauge } x \text { no. of feeder } x \text { stitch length } x \text { efficiency } x \text { rpm } \times 1440}{10 \times 2.54 \times 36 \times 840 \times \text { Yarn Count } \times 2.2046}$

$=\frac{3.1416 \times 34 \times 24 \times 102 \times 2.75 \times 0.85 \times 25 \times 1440}{10 \times 2.54 \times 36 \times 840 \times 28 \times 2.2046}$

$=464 \frac{\mathrm{kg}}{\mathrm{day}}$

Calculated production per day for a single jersey machine (machine no. 67)

$=\frac{\pi x \text { dia } x \text { gauge } x \text { no. of feeder } x \text { stitch length } x \text { ef ficiency } x \text { rpm } \times 1440}{10 \times 2.54 \times 36 \times 840 \times \text { Yarn Count } \times 2.2046}$

$=\frac{3.1416 \times 30 \times 24 \times 90 \times 2.75 \times 0.85 \times 25 \times 1440}{10 \times 2.54 \times 36 \times 840 \times 28 \times 2.2046}$

$=361 \frac{k g}{d a y}$

In non air-condition environment, actual production for machine no. P14 was $290 \mathrm{~kg} /$ day and $348 \mathrm{~kg} /$ day for machine no. J29. Whereas in air-condition environment, actual production for machine no. 35 was $380 \mathrm{~kg} /$ day and 307 $\mathrm{kg}$ /day for machine no. 67.

Efficiency losses for machine number P14

$=\frac{411-290}{411} \times 100$

$=29.44 \%$

Efficiency losses for machine number J29

$=\frac{520-348}{520} \times 100$

$=33 \%$

Efficiency losses for machine number K35

$=\frac{464-357}{464} \times 100$

$=23 \%$

Efficiency losses for machine number Z67

$=\frac{361-287}{361} \times 100$

$=20.50 \%$ 


\subsection{Causes of Production Loss and Efficiency Interruption}

Machine handling time, yarn breakage, online quality check, and needle breakages as well as inferior working environment enhance different causes. Thus, this leads to production loss for specific time span.

\subsection{Discussions}

From the above analysis and calculation, it was found that production interruption and efficiency loss is more for non air-condition working environment compared to air-condition working environment. In non aircondition knitting plant, yarn becomes dried up which causes yarn breakage and deteriorates the texture of the fabric. As yarn breakage rate is higher, machine stoppage or idle time is also lifted. All of these factors are considered in the machine handling time for a machine operator.

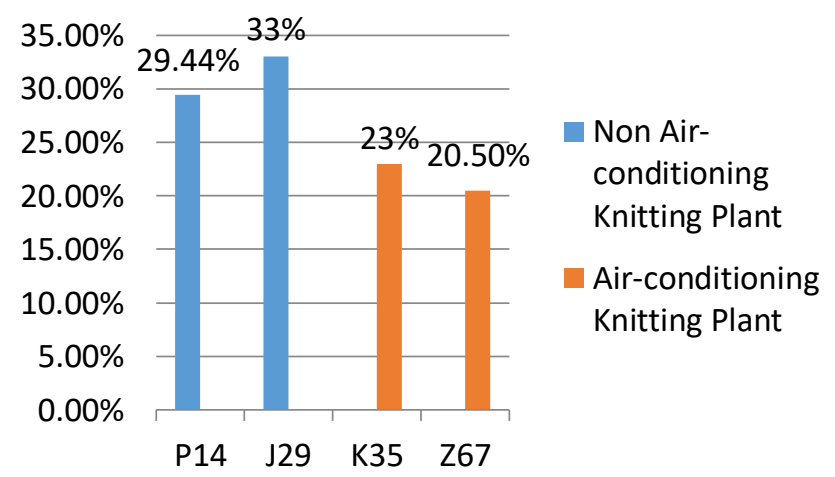

Figure 1. Efficiency loss (x-axis: machine number, y-axis: efficiency loss in percentage)

Most of the knitting faults which occur in the knit-fabric are due to yarn breakages. It can also downgrade the finished garment. Therefore, constant yarn quality is obligatory to get quality fabric.

\section{Conclusion}

Productivity is a key factor for any particular manufacturing unit to achieve their desired goal. It can measure the efficiency of the manufacturing personnel, machine, and factory as well as the organizational system in converting inputs into demanded outputs. It is an inevitable parameter which directly influences the production performance of a workplace. Here, it is clearly visible that working environment influences productivity and results on efficiency losses. Uncomfortable working condition not only affects the machine and materials nut, but it also demotivates man which increases machine handling time.

There are other conditions like knitting parameters, different brand of knitting machine, safety rpm, skilled worker, and sound wage-rate which affects the efficiency of knitting machine. 


\section{References:}

1. Anbumani, N. (2007). Knitting Fundamentals, Machines and Structure and Development, First Edition, New Age International Publishers, New Delhi, India.

2. Fatkic, E., Gersak, J., \& Ujevic, D. (2011). Influence of knitting parameters on the mechanical properties of plain jersey weft knitted fabrics. Fibres Textil East Eur1; 19:87-91.

3. Horrocks, A.R. \& Anand, S.C. Hand book of Technical textiles, Woodhead publishing Ltd, pp. 105.

4. Iyer, Mammel, \& Schach. Circular Knitting, second edition.

5. Prasad \& Kumar (2016). A New Approach for Machine Gauge\& Production Calculation of Various Kinds of Rib and interlock Knitted Fabric Structure. Journal of Textile Science and Technology, 2, 31-36.

6. Ray, S.C. (2011). Fundamentals and Advances in Knitting Technology.Woodhead Publishing India Pvt. Limited, New Delhi.

7. Spencer David .J. (2001). Knitting Technology, Third Edition, Woodhead Publishing Limited, Cambridge, England. 